\title{
PRODUÇÃO DE MUDAS DE IPÊ-BRANCO EM DIFERENTES SUBSTRATOS
}

\author{
Marichel Canazza de Macedo ${ }^{1}$, Yara Brito Chaim Jardim Rosa², Edgard Jardim Rosa Junior ${ }^{3}$, \\ Silvana de Paula Quintão Scalon ${ }^{4}$, Mariana Bento Tatara ${ }^{5}$
}

(recebido: 20 de outubro de 2009; aceito: 30 de novembro de 2010)

\begin{abstract}
RESUMO: Objetivou-se, com este trabalho, avaliar a emergência de plântulas e o crescimento no viveiro de mudas de ipê-branco (Tabebuia roseo-alba (Ridl.) Sandwith) em diferentes substratos. Foram realizados dois experimentos independentes. O estudo da emergência foi realizado em seis substratos: 1- Plantmax ${ }^{\circledR}$ - P; 2- vermiculita - V; 3- areia - A; 4- solo + areia - SA (1:1); 5solo + casca de arroz carbonizada - SC (1:1); 6- solo + areia + casca de arroz carbonizada - SAC (2:1:1) (v/v), sendo utilizado o delineamento experimental em blocos casualizados (DBC) com três repetições. O estudo do crescimento no viveiro foi realizado em DBC com cinco substratos e cinco repetições, sendo utilizados os seguintes substratos: 1- solo + areia - SA (1:1); 2- solo + cama de frango semidecomposta - SCF (1:1); 3- solo + casca de arroz carbonizada - SC (1:1); 4- solo + areia + cama de frango semidecomposta-SACF (1:1:1); 5- solo + areia + casca de arroz carbonizada - SAC (1:1:1) (v/v). Os maiores valores de porcentagem final de emergência, índice de velocidade de emergência e altura das plântulas foram observados nos substratos P, V, SC e SAC. Os maiores valores de altura, diâmetro do colo, índice de clorofila, área foliar, comprimento da maior raiz e massa seca da parte aérea e radicular das mudas foram observados nos substratos SACF e SCF. Recomenda-se a utilização de P, V, SC ou SAC para germinação e emergência de plântulas e SACF ou SCF para a produção de mudas de ipê-branco.
\end{abstract}

Palavras-chave: Tabebuia roseo-alba, germinação, crescimento inicial, resíduos agroindustriais.

\section{GROWTH OF WHITE TABEBUIA SEEDLINGS IN DIFFERENT SUBSTRATES}

\begin{abstract}
The objective of this work was to evaluate the white tabebuia (Tabebuia roseo-alba (Ridl.) Sandwith) seedlings emergence and growth in the beds according to different substrates. Two independent experiments were conducted. The emergence study was carried out in six substrates: 1-Plantmax $($; 2-vermiculite; 3- sand; 4- soil + sand (1:1); 5- soil + carbonized rice husk (1:1); 6- soil + sand + carbonized rice husk $(2: 1: 1)(\mathrm{v} / \mathrm{v})$, and the experiment was set up according to a three-replicate randomized completeblock design. The growth study of seedlings was carried out according to a five-replicate randomized complete-block design with five substrates: 1- soil + sand (1:1); 2- soil + semi decomposed chicken manure (1:1); 3- soil + carbonized rice husk (1:1); 4- soil + sand + semi decomposed chicken manure (1:1:1); 5- soil + sand + carbonized rice husk (1:1:1) $(\mathrm{v} / \mathrm{v})$. The height results of seedling emergence, emergence speed index and the stem height were observed with Plantmax ${ }^{\circledR}$, vermiculite, soil + carbonized rice husk and soil + sand + carbonized rice husk. The best results of seedling height, stem diameter, chlorophyll index, leaf area, root length and the stem dry mass weight and root were observed in the substrates with semi decomposed chicken manure. It is recommended the use of P, V, SC or SAC for seedling germination and emergence and SACF or SCF for seedling growth of white tabebuia.
\end{abstract}

Key words: Tabebuia roseo-alba, germination, initial growth, agroindustrial wastes.

\section{INTRODUÇÃo}

Muitas espécies arbóreas nativas são potencialmente aptas para o cultivo racional, podendo servir para diversos fins, quer seja pelo valor ornamental, madeireiro, alimentício ou de preservação. Como o plantio dessas espécies exige conhecimentos técnicos nem sempre disponíveis (SOUZA et al., 2005), a melhoria do sistema de produção de mudas é necessária devido ao aumento da procura para a produção comercial, e para a recuperação de áreas degradadas (NIETSCHE et al., 2004). O êxito no estabelecimento de plantios depende, dentre outros fatores,

\footnotetext{
${ }^{1}$ Bacharel em Ciências Biológicas, Doutoranda em Produção Vegetal - Programa de Pós-Graduação em Agronomia - Faculdade de Ciências Agrárias - Universidade Federal da Grande Dourados - Rodovia Dourados-Itahum, Km 12 - Cx.P. 533 - $79804-970$ - Dourados, MS marichelcanazza@zipmail.com.br

${ }^{2}$ Agrônoma, Professora Doutora em Energia na Agricultura - Universidade Federal da Grande Dourados - Rodovia Dourados-Itahum, Km 12 Cx.P. 533 - 79804-970 - Dourados, MS - yararosa@ufgd.edu.br

${ }^{3}$ Agrônomo, Professor Doutor em Energia na Agricultura - Universidade Federal da Grande Dourados - Rodovia Dourados-Itahum, Km 12 Cx.P. 533 - 79804-970 - Dourados, MS - edgardjunior@ufgd.edu.br

${ }^{4}$ Licenciada em Ciências Biológicas, Professora Doutora em Ciências dos Alimentos - Universidade Federal da Grande Dourados - Rodovia Dourados-Itahum, Km 12 - Cx.P. 533 - 79804-970 - Dourados, MS - silvana.scalon@ufgd.edu.br

${ }^{5}$ Bacharel em Ciências Biológicas, Mestranda em Produção Vegetal - Programa de Pós-Graduação em Agronomia - Faculdade de Ciências Agrárias - Universidade Federal da Grande Dourados - Rodovia Dourados-Itahum, Km 12 - Cx.P. 533 - $79804-970$ - Dourados, MS marianabtatara@gmail.com.br
}

Cerne, Lavras, v. 17, n. 1, p. 95-102, jan./mar. 2011 
da escolha do substrato, uma vez que ele exerce influência sobre a emergência de plântulas e sobre a qualidade das mudas (ALEXANDRE et al., 2006; WAGNER JUNIOR et al., 2006).

Inúmeros materiais podem ser empregados como substrato, devendo-se levar em conta suas características físico-químicas, sua disponibilidade e seu custo (NICOLOSSO et al., 2000). Entretanto, a falta dessas informações limita a exploração de materiais alternativos, tornando sua escolha e seu manejo um problema técnico para os viveiristas (BACKES; KÄMPF, 1991).

Assim, visando minimizar gastos com mão de obra e erros na formulação das misturas, são comercializados substratos específicos para o desenvolvimento adequado de determinadas espécies vegetais, tais como o Plantmax $\mathbb{R}$ e a vermiculita (OLIVEIRA et al., 1993). Entretanto, a crescente preocupação em tornar os sistemas agrícolas mais sustentáveis tem impulsionado o uso de resíduos agroindustriais como alternativas aos substratos comerciais (TERRA et al., 2007). Dentre os subprodutos agroindustriais, a casca de arroz tem sido utilizada na composição de substratos, tanto na forma carbonizada quanto na composição de cama semidecomposta de frango.

Recentemente, muita atenção tem sido dada para o plantio de espécies arbóreas nativas, porém existem poucas informações sobre a germinação e a produção de mudas de ipê-branco, Tabebuia roseo-alba (Ridl.) Sandwith.

O ipê-branco apresenta características ornamentais, não somente pelo exuberante florescimento, que pode ocorrer mais de uma vez por ano, mas também pela folhagem de cor verde azulada e pela forma piramidal da copa. É uma espécie bastante recomendada para paisagismo em geral e útil para a arborização de ruas e avenidas devido ao seu porte não muito grande. Em função de sua adaptação a terrenos secos e pedregosos, é também utilizada, nestes ambientes, para reflorestamentos destinados à recomposição da vegetação arbórea (LORENZI, 2000). A emergência de plântulas de $T$. roseo-alba ocorre de 8 a 18 dias após a semeadura, e a germinação é superior a 40\% (LORENZI, 2000). Estudos realizados com esta espécie, sob condições laboratoriais, indicaram o alto percentual germinativo das suas sementes (86,6\%) numa faixa de temperatura de 15 a $35^{\circ} \mathrm{C}$ (SANTOS et al., 2005).

Nesse sentido, objetivou-se, com este trabalho, avaliar a emergência das sementes e o crescimento em viveiro de mudas de ipê-branco em diferentes substratos.

\section{MATERIAL E MÉTODOS}

O experimento foi conduzido na área de Jardinocultura da Faculdade de Ciências Agrárias (FCA) da Universidade Federal da Grande Dourados (UFGD), localizada no município de Dourados-MS, durante o período de outubro de 2007 a janeiro de 2008.

A cidade de Dourados está localizada nas coordenadas $22^{\circ} 13^{\prime} 16^{\prime} \mathrm{S}$ e $54^{\circ} 48^{\prime} 02^{\prime} \mathrm{W}$ com altitude média de 452 m e média da precipitação total anual de 1250 a $1500 \mathrm{~mm}$. O clima regional é do tipo Cwa mesotérmico úmido, segundo a classificação de Köppen (1948), e o solo é do tipo Latossolo Vermelho Distroférrico. Durante o período experimental, a temperatura dentro do viveiro variou de 30,1 a $19,1{ }^{\circ} \mathrm{C}$.

Frutos maduros de Tabebuia roseo-alba, em estágio inicial de deiscência, foram colhidos de matrizes localizadas no campus da UFGD. Após a colheita, os frutos foram mantidos em temperatura ambiente, em local sombreado por dois dias para completarem sua deiscência e facilitar a extração das sementes.

Foram utilizados como constituintes dos substratos: 1) substrato comercial Plantmax ${ }^{\circledR}$; 2) vermiculita fina de granulometria entre 2 a $10 \mathrm{~mm}$; 3) areia de textura grossa peneirada em malha de $2 \mathrm{~mm}$; 4) solo proveniente do horizonte B de um Latossolo Vermelho Distroférrico peneirado em peneira de malha de $2 \mathrm{~mm}$; 5) casca de arroz carbonizada e 6) cama de frango material semidecomposto constituído por casca de arroz e dejetos de frango de corte. A proporção dos constituintes dos substratos foi feita em relação ao volume e, para que os objetivos propostos fossem alcançados, foram instalados dois experimentos independentes.

\subsection{Efeito de diferentes substratos na germinação de sementes de ipê-branco}

A semeadura foi realizada em bandejas de polietileno, providas de 20 células de $21 \mathrm{~cm}^{3}$, preenchidas com os seguintes substratos: 1- substrato comercial Plantmax ${ }^{\circledR}$ - P; 2- vermiculita - V; 3- areia - A; 4- solo + areia - SA (1:1); 5- solo + casca de arroz carbonizada - SC (1:1); 6- solo + areia + casca de arroz carbonizada - SAC (2:1:1) (v/v). A seguir, as bandejas foram acondicionadas em viveiro coberto com tela de $50 \%$ de sombreamento e provido de sistema de irrigação por micro aspersão.

Durante o período experimental, os substratos receberam uma lâmina de água de $6 \mathrm{~mm}$ dividida em duas irrigações diárias. A cada dois dias, foi contado o número

Cerne, Lavras, v. 17, n. 1, p. 95-102, jan./mar. 2011 
de plântulas emergidas e, posteriormente, calculada a porcentagem de emergência $(\% \mathrm{E})$. Aos 18 dias após a semeadura (DAS), as plântulas foram removidas dos substratos e lavadas em água corrente para avaliação da altura (H), comprimento da raiz (CR) e massa seca da parte aérea (MSPA) e da raiz (MSR). Foram obtidos também a porcentagem final de emergência $(\% \mathrm{FE})$ e o índice de velocidade de emergência (IVE) das plântulas, conforme Popinigis (1985).

Para as características H, CR, MSPA, MSR, \%FE e IVE foi utilizado o delineamento experimental em blocos casualizados (DBC) com seis tratamentos (substratos) e três repetições constituídas de 20 sementes cada. Para a característica $\% \mathrm{E}$, os tratamentos foram arranjados em esquema de parcelas subdivididas, sendo as parcelas constituídas pelas épocas de avaliação e as subparcelas pelos substratos.

Todas as características foram submetidas à análise de variância, sendo que os valores de porcentagem de emergência $(\% \mathrm{E})$ foram previamente transformados em $\sqrt{ }(\mathrm{x}+1)$ (BANZATO; KRONKA, 1992). Posteriormente as médias foram comparadas pelo teste de Tukey a 5\% de significância e, para os valores de \% E, foram ajustadas curvas de regressão. Essas avaliações foram efetuadas com auxílio do programa computacional SAEG.

\subsection{Efeito de diferentes substratos no crescimento inicial de plantas de ipê-branco}

Plântulas de aproximadamente 30 dias de idade e obtidas a partir da semeadura em bandejas de polietileno contendo substrato Plantmax ${ }^{\circledR}$ - P foram utilizadas no presente experimento.

As mudas foram transplantadas para sacos plásticos perfurados de cor preta com capacidade de $1500 \mathrm{~cm}^{3}$, contendo os seguintes substratos: 1) solo + areia - SA $(1: 1) ; 2)$ solo + cama de frango semidecomposta - SCF $(1: 1) ; 3)$ solo + casca de arroz carbonizada - SC (1:1); 4) solo + areia + cama de frango semidecomposta - SACF $(1: 1: 1) ; 5)$ solo + areia + casca de arroz carbonizada $-\mathrm{SAC}$ $(1: 1: 1)(\mathrm{v} / \mathrm{v})$.

Em seguida, as mudas foram acondicionadas em canteiros no interior de viveiro provido de tela de $50 \%$ de sombreamento com sistema de irrigação por micro aspersão. Após 20 dias do transplante (DAT), todas as plantas foram avaliadas semanalmente, quanto à altura (medida compreendida entre a superfície do substrato e a inserção da folha mais alta) e quanto ao diâmetro do colo (medido a $1 \mathrm{~cm}$ acima da superfície do substrato com a utilização de um paquímetro digital), totalizando 7 avaliações (20, 27, 34, 41, 48, 55 e 62 DAT).

Aos 62 dias após o transplante, foi medido o índice de clorofila, as mudas foram retiradas dos sacos e o substrato totalmente removido com auxílio de água corrente. Em seguida, as mudas foram separadas em parte aérea e sistema radicular para determinação do comprimento da raiz principal, da área foliar e da massa seca da parte aérea e do sistema radicular.

Para a determinação do comprimento da maior raiz, foi utilizada uma régua graduada em milímetros. As leituras do índice de clorofila e da área foliar foram realizadas com material ainda fresco, usando-se um clorofilômetro e um integrador de área foliar, respectivamente. A seguir, as massas frescas da parte aérea e do sistema radicular foram acondicionadas separadamente em sacos de papel e colocadas para secar em estufa de circulação forçada (SOUZA et al., 2005), em temperatura de $55^{\circ} \mathrm{C}$, até peso constante para determinação das massas secas da parte aérea e do sistema radicular.

Foi utilizado o delineamento experimental em blocos casualizados (DBC) com cinco tratamentos constituídos pelos substratos e cinco repetições compostas de seis plantas cada. Para as características altura e diâmetro do colo, os tratamentos foram analisados em esquema de parcelas subdivididas, sendo as parcelas constituídas pelas 7 avaliações no tempo e as subparcelas constituídas pelos 5 substratos.

Todas as características foram submetidas à análise de variância e ,posteriormente, as médias foram comparadas pelo teste de Tukey a 5\% de significância. Para os valores de altura e diâmetro, foram ajustadas curvas de regressão. Essas avaliações foram efetuadas com auxílio do programa computacional SAEG. Os dados referentes à característica massa seca de raiz foram transformados em $\sqrt{ }(x+1)$.

\section{RESULTADOS E DISCUSSÃO}

\subsection{Efeito de diferentes substratos na germinação de sementes de ipê-branco}

A emergência das plântulas de ipê-branco iniciouse a partir do sexto dia após a semeadura (DAS) e a porcentagem máxima de emergência foi observada por volta do décimo quarto dia nos substratos $\mathrm{P}, \mathrm{V}, \mathrm{SC}$ e SAC, quando as curvas de emergência começaram a se estabilizar. Para os substratos A e SA, somente aos 18 DAS foram observados os maiores valores de $\% \mathrm{E}$ (Figura 1).

Cerne, Lavras, v. 17, n. 1, p. 95-102, jan./mar. 2011 


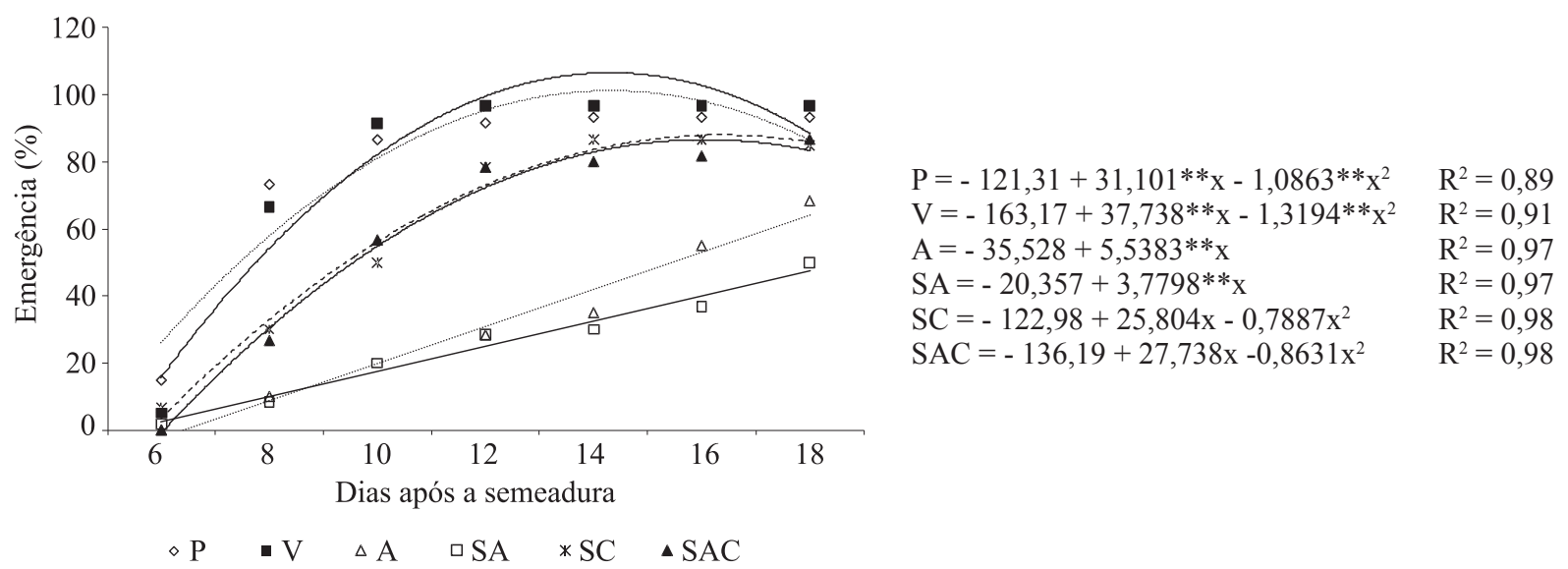

Figura 1 - Porcentagem de emergência de ipê-branco (Tabebuia roseo-alba Ridl. Sandwith) em diferentes substratos ( $\mathrm{P}=\mathrm{Plantmax}$, $\mathrm{V}=$ vermiculita, $\mathrm{A}=$ areia, $\mathrm{SA}=$ solo + areia, $\mathrm{SC}=$ solo+casca de arroz carbonizada, $\mathrm{SAC}=$ solo + areia + casca de arroz carbonizada) $\mathrm{e}$ em diferentes épocas de avaliação. UFGD, Dourados-MS, 2008.

Figure 1 - White tabebuia seedlings (Tabebuia roseo-alba Ridl. Sandwith) emergence percentage in different substrates ( $P=$ Plantmax, $V=$ vermiculite $A=$ sand, $S A=$ soil+sand, $S C=$ soil+carbonized rice husk, $S A C=$ soil+sand+carbonized rice husk and periods of evaluation. UFGD, Dourados-MS, 2008.

Os dados observados na presente pesquisa corroboram informações de Lorenzi (2000), nas quais a emergência de plântulas de ipê-branco ocorre de 8 a 18 dias após a semeadura, e a germinação é superior a 40\%. Como, em todos os substratos avaliados, foram alcançados valores de emergência maiores que $50 \%$, sugere-se que esses substratos puderam manter um teor de água satisfatório para o processo de embebição, e que, segundo Grave et al. (2007), a adequação da disponibilidade de água dos substratos associados à boa qualidade das sementes utilizadas, garante a germinação das sementes e posterior emergência das plântulas.

Houve efeito significativo $(\mathrm{P}<0,05)$ dos substratos sobre a porcentagem final de emergência $(\% \mathrm{FE})$, o índice de velocidade de emergência (IVE) e a altura (H). A \%FE foi elevada em todos os substratos exceto para solo + areia (SA). Para o IVE e altura, os maiores valores foram observados nos substratos $\mathrm{P}$ e $\mathrm{V}$ e os menores valores foram observados nos substratos A, SA e SCA. A massa seca da parte aérea (MSPA), o comprimento da raiz principal (CR) e a massa seca da raiz (MSR) não foram influenciados $(\mathrm{P}>0,05)$ pelos tipos de substrato (Tabela 1).

O efeito benéfico do Plantmax, vermiculita e casca de arroz carbonizada sobre o vigor também foi observado por outros autores para espécies arbóreas. Andrade et al. (2000) observaram que a vermiculita proporcionou maiores valores de porcentagem de germinação (69 a 89,7\%) e IVE de sementes de jenipapo (Genipa americana L.).
Para Luehea divaricata Mart. e Zucc, o uso de Plantmax ${ }^{\circledR}$ ou casca de arroz carbonizada favoreceu os maiores valores de porcentagem de emergência com médias de 91,2 e 90,0\%, respectivamente (GRAVE et al., 2007).

Por outro lado, os menores valores de altura das mudas de ipê-branco foram observados nos substratos SA e SAC. Sugere-se que esse resultado ocorra em função dos menores valores de IVE observados nesses substratos. Dessa forma, as plântulas demoraram mais tempo para emergir e, consequentemente, apresentaram menor altura em relação às plântulas emergidas nos demais substratos.

Os substratos $\mathrm{P}, \mathrm{V}, \mathrm{SC}$ e SAC provavelmente apresentam suficiente disponibilidade hídrica, oferecendo, dessa forma, as condições necessárias para maximizar a germinação das sementes e posterior emergência de plântulas de T. roseo-alba.

\subsection{Efeito de diferentes substratos no crescimento inicial de plantas de ipê-branco}

Foi observado efeito significativo $(\mathrm{P}<0,01)$ da interação entre as épocas de avaliação e os substratos para a altura e diâmetro do colo, havendo um aumento linear dessas características, no período compreendido entre 20 e 62 dias, em todos os substratos testados. Os substratos $\mathrm{SCF}$ e SACF proporcionaram maior crescimento em altura e diâmetro do colo, quando comparados ao substrato SA (Figura 2a e b).

Cerne, Lavras, v. 17, n. 1, p. 95-102, jan./mar. 2011 
Tabela 1 - Valores médios de porcentagem final de emergência (\%FE), índice de velocidade de emergência (IVE), altura (H), comprimento da raiz (CR), massa seca da parte aérea (MSPA) e massa seca da raiz (MSR) de plântulas de ipê-branco (Tabebuia roseo-alba Ridl. Sandwith) observados aos 18 DAS em diferentes substratos. UFGD, Dourados-MS, 2008.

Table 1 - Average values of final emergence (\%FE), emergence speed index (IVE), height (H), root length (CR), stem dry matter weight (MSPA) and root dry matter weight (MSR) of white tabebuia seedlings (Tabebuia roseo-alba Ridl. Sandwith) observed after 18 DAS in different substrates. UFGD, Dourados-MS, 2008.

\begin{tabular}{lcccccc}
\hline Substratos & $\% \mathrm{FE}$ & IVE & $\mathrm{H}(\mathrm{cm})$ & CR $(\mathrm{cm})$ & MSPA $(\mathrm{g})$ & MSR $(\mathrm{g})$ \\
\hline P & $93,33 \mathrm{a}$ & $2,33 \mathrm{a}$ & $3,59 \mathrm{a}$ & $5,96 \mathrm{a}$ & $0,0538 \mathrm{a}$ & $0,0081 \mathrm{a}$ \\
V & $96,66 \mathrm{a}$ & $2,32 \mathrm{a}$ & $3,77 \mathrm{a}$ & $5,20 \mathrm{a}$ & $0,0289 \mathrm{a}$ & $0,0064 \mathrm{a}$ \\
$\mathrm{A}$ & $70,00 \mathrm{ab}$ & $0,85 \mathrm{~b}$ & $2,15 \mathrm{~b}$ & $3,88 \mathrm{a}$ & $0,0176 \mathrm{a}$ & $0,0066 \mathrm{a}$ \\
SA & $50,00 \mathrm{~b}$ & $0,82 \mathrm{~b}$ & $2,02 \mathrm{~b}$ & $4,66 \mathrm{a}$ & $0,0167 \mathrm{a}$ & $0,0033 \mathrm{a}$ \\
SC & $86,66 \mathrm{a}$ & $1,76 \mathrm{ab}$ & $2,85 \mathrm{ab}$ & $4,87 \mathrm{a}$ & $0,0227 \mathrm{a}$ & $0,0048 \mathrm{a}$ \\
SAC & $86,66 \mathrm{a}$ & $1,72 \mathrm{ab}$ & $2,86 \mathrm{ab}$ & $4,07 \mathrm{a}$ & $0,0186 \mathrm{a}$ & $0,0027 \mathrm{a}$ \\
Média & 80,55 & 1,63 & 2,87 & 4,77 & 0,2600 & 0,5300 \\
CV (\%) & 8,528 & 27,795 & 14,146 & 16,092 & 0,771 & 0,105 \\
\hline
\end{tabular}

Médias seguidas de mesma letra, na coluna, não diferem entre si (Tukey 5\%).

$\mathrm{P}=$ Plantmax $\mathbb{R} ; \mathrm{V}=$ vermiculita; $\mathrm{A}=$ areia; $\mathrm{SA}=$ solo + areia; $\mathrm{SC}=$ solo + casca de arroz carbonizada; $\mathrm{SAC}=$ solo + areia + casca de arroz carbonizada.

Means followed by the same letter, in the column, do not differ among themselves.

$P=$ Plantmax ${ }^{\circledR}, V=$ vermiculite, $A=$ sand,$S A=$ soil + sand,$S C=$ soil + carbonized rice husk, $S A C=$ soil + sand + carbonized rice husk.

a)
$\mathrm{SA}=-3,5219+0,1219 * * \mathrm{x}$
$\mathrm{SACF}=-13,782+0,3656 * * \mathrm{x}$
$\mathrm{SCF}=-13,588+0,4011 * * \mathrm{x}$
$\mathrm{SAC}=-6,2451+0,1965^{* *} \mathrm{x}$
$\mathrm{SC}=-4,242+0,1892 * * \mathrm{x}$

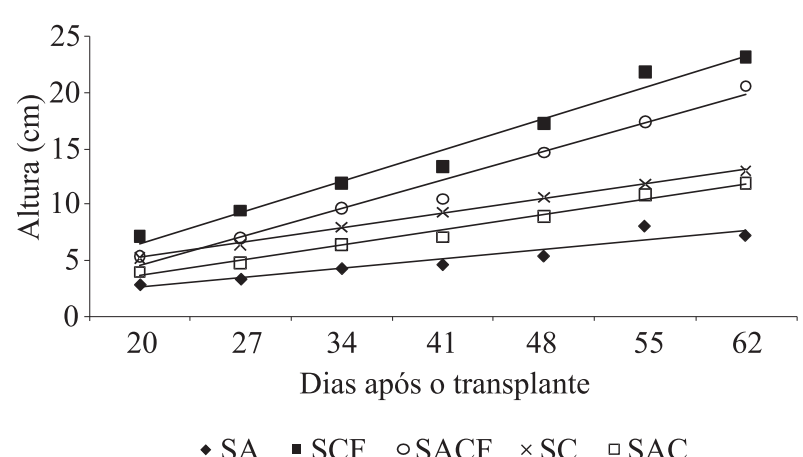

b)

$\begin{array}{ll}\mathrm{SA}=1,0686+0,017 * * \mathrm{x} & \mathrm{R}^{2}=0,95 \\ \mathrm{SACF}=0,5507+0,065 * \mathrm{x} & \mathrm{R}^{2}=0,97 \\ \mathrm{SCF}=0,8132+0,0625 * * \mathrm{x} & \mathrm{R}^{2}=0,99 \\ \mathrm{SAC}=0,8857+0,0278 * \mathrm{x} & \mathrm{R}^{2}=0,96 \\ \mathrm{SC}=0,9764+0,0307 * * \mathrm{x} & \mathrm{R}^{2}=0,92\end{array}$

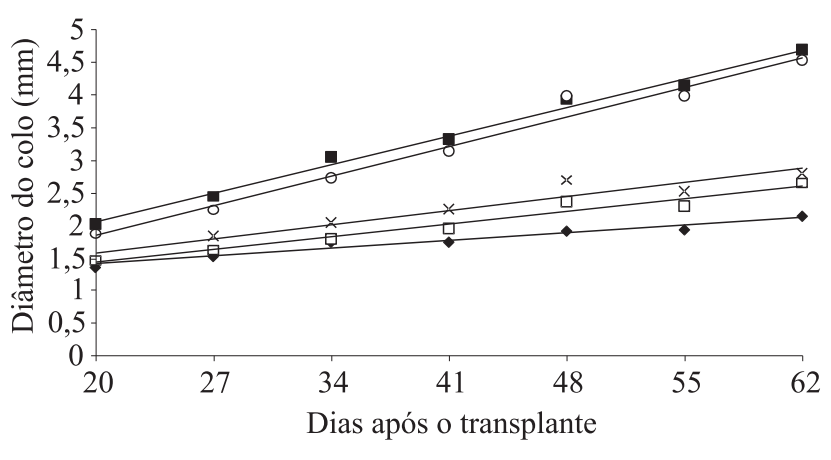

- $\mathrm{SA}-\mathrm{SCF} \quad \circ \mathrm{SACF} \times \mathrm{SC} \quad \square \mathrm{SAC}$

Figura 2 - Altura (a) e diâmetro do colo (b) de mudas de ipê-branco (Tabebuia roseo-alba Ridl.Sandwith) em diferentes substratos $(\mathrm{SA}=$ solo+areia, $\mathrm{SCF}=$ solo+cama de frango semidecomposta, $\mathrm{SC}=$ solo+casca de arroz carbonizada, $\mathrm{SACF}=$ solo + areia + cama de frango semidecomposta, $\mathrm{SAC}=$ solo+areia + casca de arroz carbonizada). UFGD, Dourados-MS, 2008.

Figure 2 - White tabebuia seedlings (Tabebuia roseo-alba Ridl. Sandwith) height (a) and stem diameter (b) in different substrates $(S A=$ soil+sand, $S C F=$ soil +semi decomposed chicken manure, $S C=$ soil+carbonized rice husk, $S A C F=$ soil + sand + semi decomposed chicken manure, SAC= soil+sand+carbonized rice husk). UFGD, Dourados-MS, 2008. 
Resultados semelhantes foram observados no cultivo de canafístula (Cassia grandis L.), em que os maiores valores de altura foram alcançados nos substratos contendo matéria orgânica (CARVALHO FILHO et al., 2002). Mudas de Eugenia dysenterica DC. também apresentaram os maiores valores de altura, quando cultivadas nos substratos contendo solo + areia e solo + areia + esterco de curral (NIETSCHE et al., 2004).

$\mathrm{O}$ diâmetro do colo tem sido reconhecido como um dos melhores indicadores de padrão de qualidade. As mudas de pequeno diâmetro e muito altas são consideradas de qualidade inferior às menores, mas com maior diâmetro de colo. Um maior diâmetro do colo, segundo Sturion e Antunes (2000), citados por Grave et al. (2007), está associado a uma maior sobrevivência e crescimento mais acentuado do sistema radicular e da parte aérea da muda após o plantio.

$\mathrm{Na}$ Tabela 2, são apresentados os resultados relativos ao índice de clorofila (IC), área foliar (AF), comprimento da raiz (CR) e massa seca da parte aérea (MSPA), massa seca das raízes (MSR) e taxa de crescimento (TC) aos 62 dias após o transplante. Também, para estas características, os substratos SCF e SACF proporcionaram os maiores valores.

Em relação ao IC, observa-se que as mudas de ipêbranco cultivadas nos substratos SC e SAC apresentaram os menores valores em relação aos demais substratos. Visivelmente, as mudas cultivadas nos substratos SCF e SACF apresentaram coloração verde intensa, enquanto aquelas cultivadas nos substratos SC e SAC apresentaram a coloração mais clara.

Os substratos SCF e SACF proporcionaram maior área foliar, comprimento de raiz e biomassa da parte aérea e radicular (Tabela 2), provavelmente em virtude da maior disponibilidade de água e nutrientes. O maior desenvolvimento da raiz possibilitou maior absorção de água e nutrientes, ocasionando maior crescimento da parte aérea nesses substratos.

Em mudas cultivadas nos substratos SC e SAC, houve menor desenvolvimento radicular, o que refletiu em menor crescimento da parte aérea quando comparado com as mudas cultivadas nos substratos SCF e SACF. Trigueiro e Guerrini (2003), estudando mudas de eucalipto cultivadas em substratos compostos por casca de arroz carbonizada, ressaltam que os menores valores de área foliar foram devidos à menor capacidade de retenção de água conferida pela casca de arroz, ocasionando uma deficiência hídrica nas plantas.

A taxa de crescimento absoluto representa, segundo Benincasa (1988), a velocidade de crescimento em altura das plântulas e pode ser usada para estimar a velocidade média de crescimento ao longo do período de observação.

Tabela 2 - Valores médios de índice de clorofila (ICL), área foliar (AF), comprimento da raiz (CR), massa seca da parte aérea (MSPA), massa seca da raiz (MSR) e taxa de crescimento em altura (TC) de plantas ipê-branco (Tabebuia roseo-alba Ridl. Sandwith) aos 62 dias após o transplante. UFGD, Dourados-MS, 2008.

Table 2 - Average values of chlorophyll index (ICL), leaf area (AF), root length (CR), stem dry mass weight (MSPA), root dry mass weight (MSR) and height growth rate (TC) of white tabebuia seedlings (Tabebuia roseo-alba Ridl. Sandwith) in different substrates 62 days after the transplanting. UFGD, Dourados-MS, 2008.

\begin{tabular}{lcccccc}
\hline Substratos & ICL & $\mathrm{AF}\left(\mathrm{cm}^{2}\right)$ & $\mathrm{CR}(\mathrm{cm})$ & MSPA $(\mathrm{g})$ & MSR $(\mathrm{g})$ & $\mathrm{TC}(\mathrm{cm})$ \\
\hline SA & $30,92 \mathrm{ab}$ & $70,622 \mathrm{~b}$ & $11,11 \mathrm{c}$ & $0,243 \mathrm{~b}$ & $0,080 \mathrm{~b}$ & 0,73 \\
SCF & $35,18 \mathrm{a}$ & $472,250 \mathrm{a}$ & $25,00 \mathrm{a}$ & $2,265 \mathrm{a}$ & $0,766 \mathrm{a}$ & 2,68 \\
SC & $25,13 \mathrm{c}$ & $134,252 \mathrm{~b}$ & $18,72 \mathrm{~b}$ & $0,544 \mathrm{~b}$ & $0,276 \mathrm{~b}$ & 1,31 \\
SACF & $35,44 \mathrm{a}$ & $433,014 \mathrm{a}$ & $21,04 \mathrm{ab}$ & $2,141 \mathrm{a}$ & $0,683 \mathrm{a}$ & 2,54 \\
SAC & $27,56 \mathrm{bc}$ & $124,080 \mathrm{~b}$ & $15,57 \mathrm{bc}$ & $0,506 \mathrm{~b}$ & $0,192 \mathrm{~b}$ & 1,33 \\
Média & 30,84 & 246,843 & 18,292 & 1,140 & 0,399 & - \\
CV (\%) & 8,75 & 18,710 & 16,697 & 18,375 & 20,616 & - \\
\hline
\end{tabular}

Médias seguidas de mesma letra, na coluna, não diferem entre si (Tukey 5\%).

$\mathrm{SA}=$ solo+areia, $\mathrm{SCF}=$ solo + cama de frango semidecomposta, $\mathrm{SC}=$ solo + casca de arroz carbonizada, $\mathrm{SACF}=$ solo + areia + cama de frango semi-decomposta, $\mathrm{SAC}=$ solo + areia + casca de arroz carbonizada

Means followed by the same letter, in the column, do not differ among themselves (Tukey Test 5\%).

$S A=$ soil+sand, $S C F=$ soil+semi decomposed chicken manure, $S C=$ soil+carbonized rice husk, $S A C F=$ soil+sand+semi decomposed chicken manure, $S A C=$ soil + sand + carbonized rice husk.

Cerne, Lavras, v. 17, n. 1, p. 95-102, jan./mar. 2011 
Dessa forma, no período compreendido entre 20 e 62 dias após o transplante, as plantas de ipê-branco apresentaram um crescimento rápido nos substratos SCF e SACF, tendo um incremento médio em altura de 2,68 e $2,54 \mathrm{~cm}$ por semana, respectivamente, enquanto que as plântulas cultivadas no substrato SA tiveram um incremento em altura de $0,73 \mathrm{~cm}$ por semana. Sugere-se que o menor crescimento em altura, no substrato AS, seja devido à ausência de nutrientes, visto que não foram efetuadas adubações de cobertura durante o experimento (NIETSCHE et al. 2004).

As plantas cultivadas no substrato SA apresentaram resultados inferiores em todos as características de qualidade analisadas em relação aos demais substratos, exceto para o índice de clorofila.

\section{CONCLUSÕES}

Os substratos Plantmax, vermiculita, solo + casca de arroz e solo + areia + casca o das sementes e a emergência de arroz carbonizada maximizaram a emergência das plântulas. Os substratos solo + cama de frango e solo + areia + cama de frango proporcionaram o maior crescimento das mudas.

\section{AGRADECIMENTOS}

À Fundação de Desenvolvimento Científico e Tecnológico do Mato Grosso do Sul (FUNDECT) e à CAPES pelo apoio financeiro e pela concessão de bolsas.

\section{REFERÊNCIAS}

ALEXANDRE, R. S.; WAGNER JUNIOR, A.; NEGREIROS, J. R. S.; BRUCKNER, C. H. Estádio de maturação dos frutos e substratos na germinação de sementes e desenvolvimento inicial de plântulas de jabuticabeira. Revista Brasileira de Agrociência, Pelotas, v. 12, n. 2, p. 227-230, abr./jun. 2006

ANDRADE, A. C. S.; SOUZA, A. F.; RAMOS, F. N.; PEREIRA, T. S.; CRUZ, A. P. M. Germinação de sementes de jenipapo: temperatura, substrato e morfologia do desenvolvimento pós-seminal. Pesquisa Agropecuária Brasileira, Brasília, v. 35, n. 3, p. 609-615, mar. 2000.

BACKES, M. A.; KÄMPF, A. N. Substratos à base de composto de lixo urbano para a produção de plantas ornamentais. Pesquisa Agropecuária Brasileira, Brasília, v. 26, n. 5, p. 753-758, 1991
BANZATO, D. A.; KRONKA, S. N. Experimentação agrícola. 2. ed. Jaboticabal: FUNEP, 1992. 247 p.

BENINCASA, M. M. P. Análise de crescimento de plantas: noções básicas. Jaboticabal: FUNEP, 1988. 42 p.

CARVALHO FILHO, J. L. S.; ARRIGONI-BLANK, M. F.; BLANK, A. F.; AMÂNCIO, V. F. Produção de mudas de Cassia grandis L. em diferentes ambientes, recipientes e misturas de substratos. Revista Ceres, Viçosa, v. 49, n. 28, p. 341-352, 2002.

GRAVE, F.; FRANCO, E. T. H.; PACHECO, J. P.; SANTOS, S. R. Crescimento de plantas jovens de açoita-cavalo em quatro diferentes substratos. Ciência Florestal, Santa Maria, v. 17, n. 4, p. 289-298, out./dez. 2007.

KÖPPEN, W. Climatologia: com um estudio de los climas de la tierra. México: Fondo de Cultura Económica, 1948. 478 p.

LORENZI, H. Árvores brasileiras: manual de identificação e cultivo de plantas arbóreas nativas do Brasil. Nova Odessa: Instituto Plantarum, 2000. 367 p.

NICOLOSSO, F. T.; FORTUNATO, R. P.; ZANCHETTI, F.; CASSOL, L. F.; EISINGER, S. M. Recipientes e substratos na produção de mudas de Maytenus ilicifolia e Apuleia leiocarpa. Ciência Rural, Santa Maria, v. 30, n. 6, p. 987-992, 2000.

NIETSCHE, S.; GONÇALVES, V. D.; PEREIRA, M. C. T.; SANTOS, F. A.; ABREU, S. C.; MOTA, W. F. Tamanho da semente e substratos na germinação e crescimento inicial de mudas de cagaiteira. Ciência e Agrotecnologia, Lavras, v. 28, n. 6, p. 1321-1325, nov./dez. 2004.

OLIVEIRA, R. P.; SCIVITTARO, W. B.; VASCONCELLOS, L. A. B. C. Avaliação de mudas de maracujazeiro em função do substrato e do tipo de bandeja. Scientia Agrícola, Piracicaba, v. 50, n. 2, p. 261-266, set. 1993.

POPINIGIS, F. Fisiologia da semente. 2. ed. Brasília: ABRATES, 1985. 298 p.

SANTOS, D. L.; SUGAHARA, V. Y.; TAKAKI, M. Efeitos da luz e da temperatura na germinação de sementes de Tabebuia serratifolia (Vahl). Nich, Tabebuia chrysotricha (Mart. Ex DC) Standl. E Tabebuia roseo-alba (Ridl) SandBignoniaceae. Ciência Florestal, Santa Maria, v. 15, n. 1, p. $87-92,2005$

Cerne, Lavras, v. 17, n. 1, p. 95-102, jan./mar. 2011 
SOUZA, V. C.; ANDRADE, L. A.; BRUNO, R. L. A.; CUNHA, A. O.; SOUZA, A. P. Produção de mudas de ipêamarelo (Tabebuia serratifolia (Vahl.) Nich.) em diferentes substratos e tamanhos de recipientes. Agropecuária Técnica, Areia, v. 26, n. 2, p. 98-108, 2005.

TERRA, S. B.; GONÇALVES, M.; MEDEIROS, C. A. B. Produção de mudas de jacarandá mimoso (Jacaranda mimosaefolia D. Don) em substratos formulados a partir de resíduos agroindustriais. Revista Brasileira de Agroecologia, Porto Alegre, v. 2, n. 1, 2007.
TRIGUEIRO, R. M.; GUERRINI, I. A. Uso de biossólido como substrato para produção de mudas de eucalipto. Scientia Florestalis, Piracicaba, n. 64, p. 150-162, dez. 2003.

WAGNER JUNIOR, A.; ALEXANDRE, R. S.;

NEGREIROS, J. R. S.; PIMENTEL, L. D.; SILVA, J. O. C.; BRUCKNER, C. H. Influência do substrato na germinação e desenvolvimento inicial de plantas de maracujazeiro amarelo (Passiflora edulis Sims f. flavicarpa Deg). Ciência e Agrotecnologia, Lavras, v. 30, n. 4, p. 643-647, jul./ago. 2006. 